\title{
Effect of Different Operating Conditions on Performance of Commercial Low-Temperature Thermoelectric Modules
}

\author{
Dipak S. Patil, R. R. Arakerimath, P. V. Walke, R. S. Shelke
}

\begin{abstract}
In the field of waste heat recovery, thermoelectric generators (TEG) are used to convert waste heat to electric power. This system attracts the attention of researchers to make it more and more efficient. The performance of thermoelectric module (TEM) plays a crucial role for thermoelectric system. Appropriate selection of thermoelectric module is one of the important criteria for enhancing the power output and conversion efficiency of thermoelectric generator. In this work, the effect of various operating conditions on performance of thermoelectric modules was experimentally investigated. Three commercial bismuth telluride (Bi2 $\left.\mathrm{Te}_{3}\right)$ thermoelectric modules (TEM1, TEM2, and TEM3) were experimentally tested to find the best performance module for low-temperature waste heat. The open-circuit voltage, power output, and conversion efficiency were measured at various operating conditions. Different operating parameters such as water mass flow rate, heater voltage, hot and cold side temperature of thermoelectric module, and external load resistance were considered for this work. An electric heater was used as a heat source and water used as a cooling fluid at heat sink side. It was observed that the TEM1 shows maximum power output of 0.31 , 0.71 and $1.25 \mathrm{~W}$, for temperature ranges of $80-100,100-150$, and $150-200{ }^{\circ} \mathrm{C}$ respectively. TEM3 achieved maximum power output $0.81 \mathrm{~W}$ for temperature range of $100-150{ }^{\circ} \mathrm{C} . \mathrm{TEM} 1, \mathrm{TEM} 2$ and TEM3 have the maximum conversion efficiency of 1.37, 0.60, and $1.64 \%$ respectively. The TEM2 having less power output and conversion efficiency for temperature range of $80-200^{\circ} \mathrm{C}$ compare to TEM1 and TEM3. However, the TEM1 is more appropriate for temperature range of $80-200^{\circ} \mathrm{C}$ and the TEM3 is also suitable for the temperature range of $80-150^{\circ} \mathrm{C}$.
\end{abstract}

Keywords: Bismuth telluride; Conversion efficiency; Open circuit voltage; Power output; Thermoelectric module.

\section{INTRODUCTION}

$\mathrm{W}$ aste heat recovery can reduce the power loss and environment pollution lead to dump waste heat [1]. Exhaust based thermoelectric generator has potential to improve the

Revised Manuscript Received on December 30, 2019.

* Correspondence Author

Mr. Dipak S. Patil*, Mechanical Department, G. H. Raisoni College of Engineering, Nagpur, India. Email: dspatil100@gmail.com

Dr Rachayya. R. Arakerimath, Mechanical Department, G. H. Raisoni College of Engineering, Pune, India. Email: rachayya.arakerimath@raisoni.net

Dr. Pramod V. Walke, Mechanical Department, G. H. Raisoni College of Engineering, Nagpur, India. Email: pramod.walke@raisoni.net

Dr. Rupesh S. Shelke, Mechanical Department, G. H. Raisoni College of Engineering, Nagpur, India. Email: rupesh.shelke@raisoni.net

(C) The Authors. Published by Blue Eyes Intelligence Engineering and Sciences Publication (BEIESP). This is an open access article under the CC BY-NC-ND license (http://creativecommons.org/licenses/by-nc-nd/4.0/) fuel economy of an engine powered vehicle [2]. Thermoelectric generators are solid state device that are used to convert thermal energy to electric energy [3]. The potential of thermoelectric generator can be improved by increasing heat energy and efficiency of thermoelectric materials [4-8]. Thermoelectric material is heavily doped semiconductors and theses are categorized in three groups according temperature range such as bismuth telluride, lead telluride and silicon germanium alloy [9]. Thermoelectric module consists of number of thermoelectric couple of p-type and n-type legs. These thermocouples are enclosed by ceramic electrical insulator [10]. Bismuth telluride, Lead telluride and silicon germanium material have highest figure of merit of $3.4 \times 10^{-3}$, $2.0 \times 10^{-3}$, and $0.8 \times 10^{-3} \mathrm{~K}^{-1}$ for low, medium and high range of temperature respectively [11-15]. Bismuth telluride is best working material for thermoelectric generator and Peltier cooling devices. Bismuth telluride has low lattice thermal conductivity and multiple low mass conducting pockets [16]. The thermoelectric properties of Seebeck coefficient, thermal resistivity and electric conductivity should be known [17]. The power generation and conversion efficiency of thermoelectric module can be enhanced by increasing electrical conductivity, Seebeck coefficient, and thermal resistivity [18]. It is observed that number of thermoelectric chips, heat exchanger, and cooling system can be optimized the thermoelectric system and thermoelectric material has been cautiously determined [19]. The open circuit voltage increases linearly with increasing the number thermoelectric couples [17]. The huge temperature difference between hot and cold side of thermoelectric module can maximize the power generation and conversion efficiency of thermoelectric system [3]. The open circuit voltage and power generation of the thermoelectric system were increased at different temperatures when thermal greases were applied at interfacing of thermoelectric module and heat exchanger surface [20]. The thermoelectric performance can be decreased by Thomson effect at low temperature difference and high Seebeck coefficient [21]. The conversion efficiency is not thoughtful matter because waste heat can be obtained at very low cost or no cost resources [5]. In the current work, the commercial thermoelectric modules of bismuth telluride $\left(\mathrm{Bi}_{2} \mathrm{Te}_{3}\right)$ were selected for experimentation. The thermoelectric module was sandwiched between heat source and heat sink of the thermal system. The heater was used as a heat source as an alternative of waste heat and water was used as a cooling fluid on the cold side of the thermoelectric module. An experimental investigation was done on different operating conditions such as water flow rate, heater voltage and external load resistance. 
During experimentation, open circuit voltage and power generation of the thermoelectric module were measured. The objective of this work is to find effect of different operating conditions on the performance of thermoelectric module for selection of appropriate thermoelectric module.

\section{THERMOELECTRIC GENERATOR (TEG)}

There are many waste heat recovery devices existing, which are generating useful energy from waste heat energy. Thermoelectric generator is one of these, which is more suitable to convert waste heat energy to electric energy. The thermoelectric system has no moving parts and silence in operation [22]. Thermoelectric module included number of P-type and N-type thermocouples which are connected electrically in series and thermally in parallel. If hot side and cold side of the thermoelectric module maintain high and low temperature respectively, electric power will be generated to an external load resistance [11]. The basic principle behind thermoelectricity is the temperature differences set the charge carriers in motion. Mostly the Seebeck effect and Peltier effect are the main physical phenomena are relative to thermoelectricity [23]. Thermoelectric performance is measured by the figure of merit $(\mathrm{Z})$, is given below:

$$
Z=\frac{\alpha^{2}}{\rho k}
$$

Where, $\alpha$ represents Seebeck coefficient $\left(V K^{-1}\right)$, $\rho$ represents electrical resistivity $(\Omega m)$ and $k$ represents thermal conductivity ( $W / m K$ ). High figure of merit shows better performance in power generation. The figure of merit is multiplied by average temperature, is become dimensionless figure of merit ( ZT ). The average temperature is given below:

$$
T=\frac{T_{h}+T_{c}}{2}
$$

Where, $T_{h}$ and $T_{c}$ are the temperature at hot and cold side of the thermoelectric module respectively. The rate of heat supply and heat rejection can be determined at the hot and cold side of the thermoelectric module respectively, is as given below [24]:

(3)

$$
Q_{h}=\alpha T_{h} I-0.5 I^{2} R+K\left(T_{h}-T_{c}\right)
$$

$$
Q_{c}=\alpha T_{c} I+0.5 I^{2} R+K\left(T_{h}-T_{c}\right)
$$

The above equations are also called ideal equations of thermoelectric study. Where, $Q_{h}$ and $Q_{c}$ are the rate of heat transfer at the hot and cold sides of thermoelectric generator respectively. $I, R$ and $K$ are represent current, internal resistance and conductance. The first term of equation 3 and 4 ( $\alpha T I$ ) is Seebeck/Peltier effect (reversible process), the second term $\left(0.5 I^{2} R\right)$ is Joule heating (irreversible process) and last term $\left(K\left(T_{h}-T_{c}\right)\right.$ is thermal conduction (irreversible process). The thermoelectric generator analogous with heat engine (first law of thermodynamic), states that the summation of all entering energies is equal to summation of all exiting energies plus work done.

$$
\begin{aligned}
& Q_{h}=Q_{c}+\dot{W} \\
& \dot{W}=Q_{h}-Q_{c} \\
& \dot{W}=\alpha I\left(T_{h}-T_{c}\right)-I^{2} R
\end{aligned}
$$

The output power $(\dot{W})$ can be determined by using external load resistance instead of internal resistance of the thermoelectric material.

$$
\dot{W}=I^{2} R_{L}=V I
$$

Where, $V$ represents voltage across the load resistance $R_{L}$ and $V$ can be determined by using following equation:

$$
V=I R_{L}=\frac{\dot{W}}{I}=\alpha\left(T_{h}+T_{c}\right)-R I
$$

The current generated in the system is as follow:

$$
I=\frac{\alpha\left(T_{h}+T_{c}\right)}{\left(R_{L}+R\right)}
$$

The thermoelectric efficiency $(\eta)$ is the ratio of power output to the power input to the system, is given by following equation:

$$
\eta=\frac{\dot{W}}{Q_{h}}=\frac{R_{L} I^{2}}{\left(\alpha T_{h} I\right)-\left(0.5 I^{2} R\right)+\left(K\left(T_{h}-T_{c}\right)\right.}
$$

The ratio of applied external load resistance to the internal resistance of thermoelectric material is an importance factor for designing of thermoelectric generator.

\section{EXPERIMENTAL SETUP}

\section{A. Thermoelectric Modules}

The properties of thermoelectric modules such as Seebeck coefficient, internal resistance and thermal conductance are required for performance evaluation of thermoelectric module. These properties are not provided to users or not available commercially. If geometric data is available, the material properties of thermoelectric module can be calculated. The geometric data included the number of thermocouples, elements cross-sectional area and elements length. Thermoelectric module selection is mostly depending on available hot side temperature of the module.

The figure of merit $(\mathrm{Z})$ is a function of operating temperature of the system. Bismuth Telluride $\left(\mathrm{Bi}_{2} \mathrm{Te}_{3}\right)$ is suitable for law to room temperature applications and easily available, has low cost [3]. The value of $\mathrm{Bi}_{2} \mathrm{Te}_{3}$ is typically one or less than one. Lead Telluride (PbTe) material is suitable for high temperature applications and Silicon Germanium (SiGe) is used for extremely high operating temperature. 

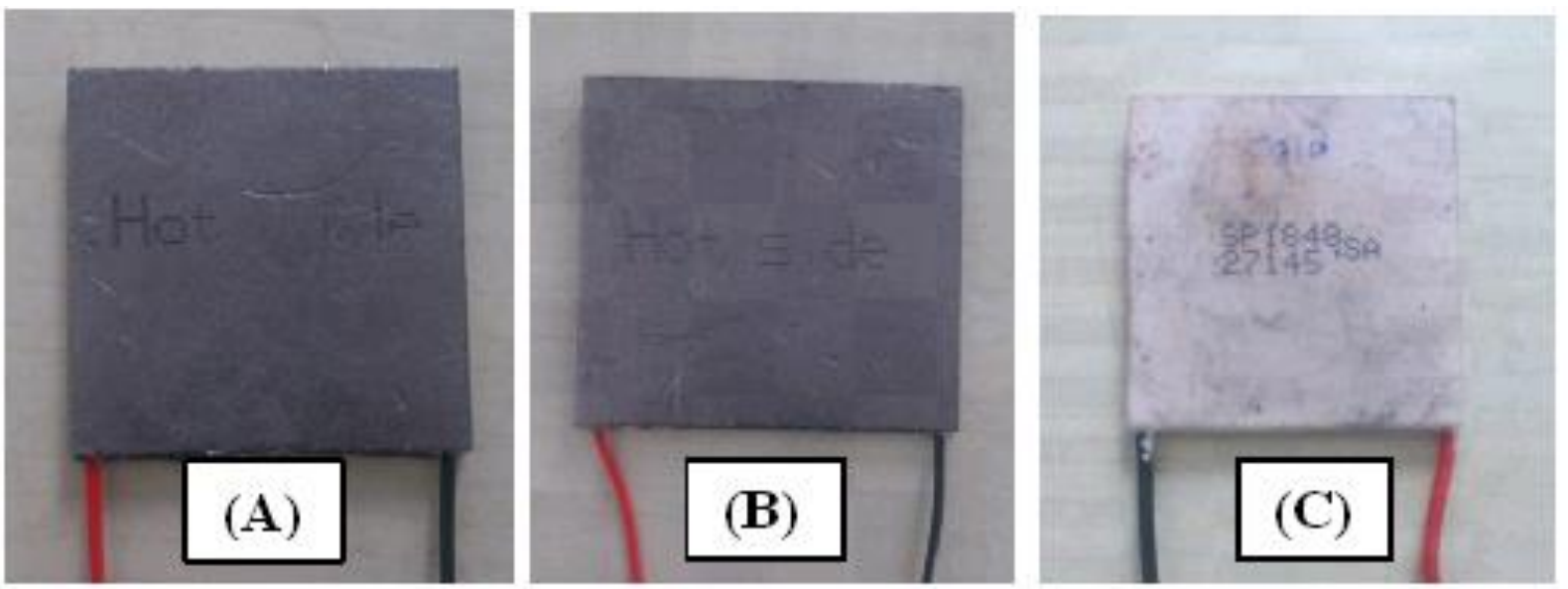

Figure 1 Photographic View of thermoelectric modules (A) TEM1- TEP1-1264-1.5 (B) TEM2- TE-MOD-22W7V-56 (C) TEM3- TEG-SP1848-27145

Table 1 Summary of thermoelectric material and module size used in low temperature thermoelectric generator

\begin{tabular}{clcc}
\hline Ref. No. & Author Name & \multicolumn{2}{c}{ Thermoelectric Module } \\
\cline { 3 - 4 } & & Material Type & $\begin{array}{c}\text { Module Size } \\
\left(\mathrm{mm}^{2}\right)\end{array}$ \\
\hline$[05]$ & Cheng-Ting Hsu et al. & $\mathrm{Bi}_{2} \mathrm{Te}_{3}$ & - \\
{$[26]$} & Shengqiang Bai et al. & $\mathrm{Bi}_{2} \mathrm{Te}_{3}$ & - \\
{$[27]$} & Calil Amaral et al. & $\mathrm{Bi}_{2} \mathrm{Te}_{3}$ & $40 \times 40 \times 4.3$ \\
{$[28]$} & Zhiqiang Niu et al. & $\mathrm{Bi}_{2} \mathrm{Te}_{3}$ & $41 \times 26 \times 3.5$ \\
{$[29]$} & Xing Niu et al. & $\mathrm{Bi}_{2} \mathrm{Te}_{3}$ & $40 \times 40 \times 4.2$ \\
{$[30]$} & Dan Dai et al. & $\mathrm{Bi}_{2} \mathrm{Te}_{3}$ & $50 \times 50 \times 3.8$ \\
{$[31]$} & Tongcai Wang et al. & $\mathrm{Bi}_{2} \mathrm{Te}_{3}$ & - \\
\hline
\end{tabular}

Table 2 Specification of the thermoelectric module 1(TEM1)

\begin{tabular}{|c|c|c|c|}
\hline Model & Model Size (mm) & Description & Value \\
\hline \multirow[t]{7}{*}{ TEP1-1264-1.5 } & $40 \times 40 \times 3.7$ & Hot Side Temperature $\left({ }^{\circ} \mathrm{C}\right)$ & 300 \\
\hline & & Cold Side Temperature $\left({ }^{\circ} \mathrm{C}\right)$ & 30 \\
\hline & & Open Circuit Voltage (V) & 9.40 \\
\hline & & Matched Load Resistance (ohms) & 2.80 \\
\hline & & Matched load output voltage (V) & 4.70 \\
\hline & & Matched load output current (A) & 1.56 \\
\hline & & Matched load output power (W) & 7.30 \\
\hline
\end{tabular}

Table 3 Specification of the thermoelectric module 2 (TEM2)

\begin{tabular}{|c|c|c|c|}
\hline Model & Model Size (mm) & Description & Value \\
\hline \multirow[t]{7}{*}{ TE-MOD-22W7V-56 } & $56 \times 56 \times 5$ & Hot Side Temperature $\left({ }^{\circ} \mathrm{C}\right)$ & 300 \\
\hline & & Cold Side Temperature $\left({ }^{\circ} \mathrm{C}\right)$ & 30 \\
\hline & & Open Circuit Voltage (V) & 14.4 \\
\hline & & Matched Load Resistance (ohms) & 2.40 \\
\hline & & Matched load output voltage (V) & 7.20 \\
\hline & & Matched load output current (A) & 3.00 \\
\hline & & Matched load output power (W) & 21.6 \\
\hline
\end{tabular}

Table 4 Specification of the thermoelectric module 3(TEM3)

\begin{tabular}{|c|c|c|c|c|c|c|c|}
\hline \multirow{2}{*}{$\begin{array}{c}\text { Model } \\
\text { TEG-SP1848-27145 }\end{array}$} & \multirow{2}{*}{$\begin{array}{c}\begin{array}{c}\text { Model Size } \\
(\mathrm{mm})\end{array} \\
40 \times 40 \times 3.7\end{array}$} & \multirow{2}{*}{$\begin{array}{l}\text { Description } \\
\text { emperature Difference, } \Delta \mathrm{T} \text {, } \\
\left.{ }^{\circ} \mathrm{C}\right)\end{array}$} & \multicolumn{5}{|c|}{ Value } \\
\hline & & & 20 & 40 & 60 & 80 & 100 \\
\hline & & Voltage, Volt (V) & 0.97 & 1.8 & 2.4 & 3.6 & 4.8 \\
\hline & & Current, I (mA) & 225 & 368 & 469 & 558 & 669 \\
\hline
\end{tabular}




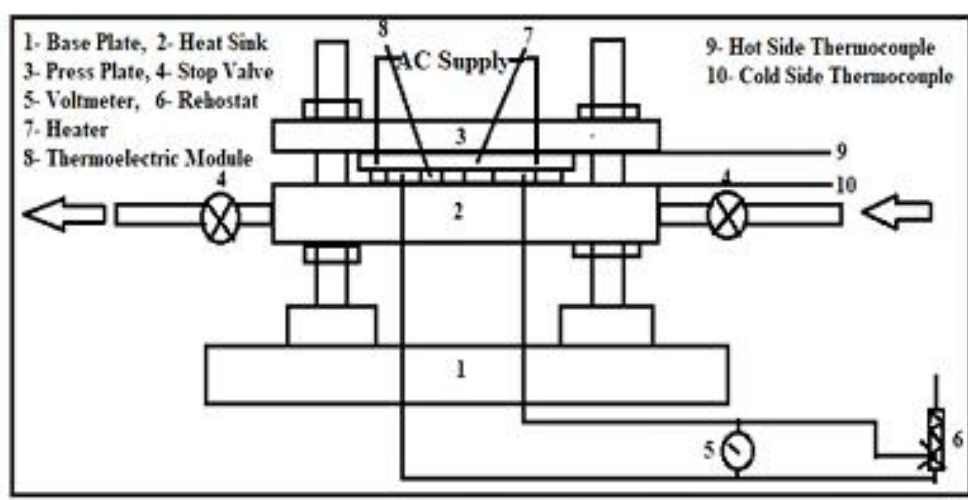

(A)

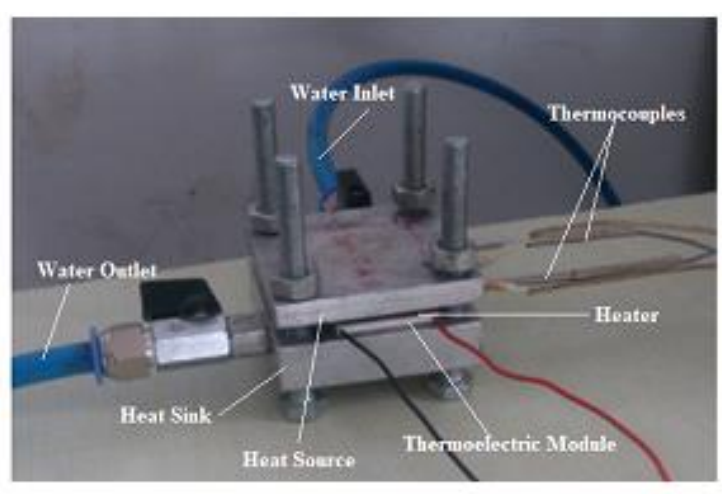

(B)

Figure 2 Experimental setup (A) Block diagram (B) Photographic view

Table 5 Factors and levels used in experimental work

\begin{tabular}{|c|c|c|c|c|c|c|c|c|c|c|}
\hline \multirow[t]{2}{*}{ Sr. No. } & \multirow[t]{2}{*}{ Factors } & \multicolumn{9}{|c|}{ Levels } \\
\hline & & 1 & 2 & 3 & 4 & $\ldots$ & 20 & 21 & $\cdots$ & 29 \\
\hline 1 & Thermoelectric module ( TEM) & TEM1 & TEM2 & TEM3 & & & & & & \\
\hline 2 & Heater voltage ( $\mathrm{H}$ or $\mathrm{h})$, (Volt) & 150 & 190 & 230 & & & & & & \\
\hline 3 & Mass flow rate of water (MFRW), (Kg/s) & 0.006 & 0.010 & 0.016 & & & & & & \\
\hline 4 & Applied load resistance, $\left(\mathrm{R}_{\mathrm{L}}\right),(\mathrm{Ohm})$ & 0 & 1 & 1.5 & 2 & $\ldots$ & 10 & 20 & $\ldots$ & 100 \\
\hline
\end{tabular}

The atoms of $\mathrm{Bi}$ and $\mathrm{Te}$ are joined with strong ionic-covalent bonds. $\mathrm{Bi}_{2} \mathrm{Te}_{3}$ has layered structure, which shows anisotropic properties. In addition, $\mathrm{Bi}_{2} \mathrm{Te}_{3}$ is easy for making P-type and N-type which is suitable for fabricating thermoelectric devices [25]. Table 1 shows that most of the researchers were selected $\mathrm{Bi}_{2} \mathrm{Te}_{3}$ thermoelectric module for power generation.

The main focus of this work was selection of appropriate thermoelectric module for low temperature $\left(150-200^{\circ} \mathrm{C}\right)$ to generate the maximum thermoelectric power. Three commercial $\mathrm{Bi}_{2} \mathrm{Te}_{3}$ thermoelectric modules were selected for this experimental work, namely TEP1-1264-1.5 (TEM1), TE-MOD-22W7V-56 (TEM2), and TEG-SP1848-27145 (TEM3). The specification of the thermoelectric module TEM1, TEM2, and TEM3 are shown in table 2, 3, and 4 respectively. Figure $1(\mathrm{~A}),(\mathrm{B})$, and $(\mathrm{C})$ show the photograph of the thermoelectric modules TEM1, TEM2 and TEM3 respectively. The hot side temperature limit of TEM1, TEM2, and TEM3 are 300,300 , and $150{ }^{\circ} \mathrm{C}$ respectively. It means that the TEM1 and TEM2 can be used up to $300^{\circ} \mathrm{C}$ but TEM3 has some restriction, it is used up to $150{ }^{\circ} \mathrm{C}$.

\section{B. Experimental System}

The layout and actual experimental setup of thermoelectric generator are shown in figure 2 (A) and (B) respectively. The experimental set up is broadly divided in to three parts, heat sink, heat source and thermoelectric module. The geometric dimension or size of heat sink was $80 \mathrm{~mm} \times 80 \mathrm{~mm} \times 20 \mathrm{~mm}$, length, width and height respectively. The heat sink has internal cavity of $45 \mathrm{~mm} \times 45 \mathrm{~mm} \times 10 \mathrm{~mm}$ with baffle plates. The baffles produce zigzag motion of the cooling fluid for keeping constant low temperature and increasing heat transfer rate. Heat sink has inlet and outlet port for cooling fluid flow. Water was used as a cold fluid to carry heat from the cold side of the thermoelectric module. An electric heater having $100 \mathrm{~W}$ capacity and $40 \mathrm{~mm} \times 40 \mathrm{~mm} \times 5 \mathrm{~mm}$ size was fixed at lower side of press plate $80 \mathrm{~mm} \times 80 \mathrm{~mm} \times 10 \mathrm{~mm}$ size, the combination of the heater and press plate acts as a heat source. The heat source and heat sink were fabricated of an aluminum material due to high thermal conductivity. In this work, three different kinds of bismuth telluride $\left(\mathrm{Bi}_{2} \mathrm{Te}_{3}\right)$ thermoelectric modules were used such as TEM1, TEM2 and TEM3.

The thermoelectric module was interfaced between heat sink and heat source by clamping with fasteners. The heater was connected to single phase alternating current supply and dimmer stat was used to control the heater voltage. The thermal grease was applied on the interfacing sides of thermoelectric module to minimize the thermal contact resistance and increase the heat transfer rate. Thermocouples (K-type) were used to measure temperature of hot and cold side of the thermoelectric module, and water temperature at inlet and outlet. The digital temperature indicator was connected to all the thermocouples to show temperature in digital form. A measuring flask was used to measure mass flow rate of cooling water.

When the thermoelectric system achieved steady state, the voltage and power output of the thermoelectric system was measured with help of voltmeter or multi-meter. An electric rheostat was used to applied external load resistance to the thermoelectric system. 


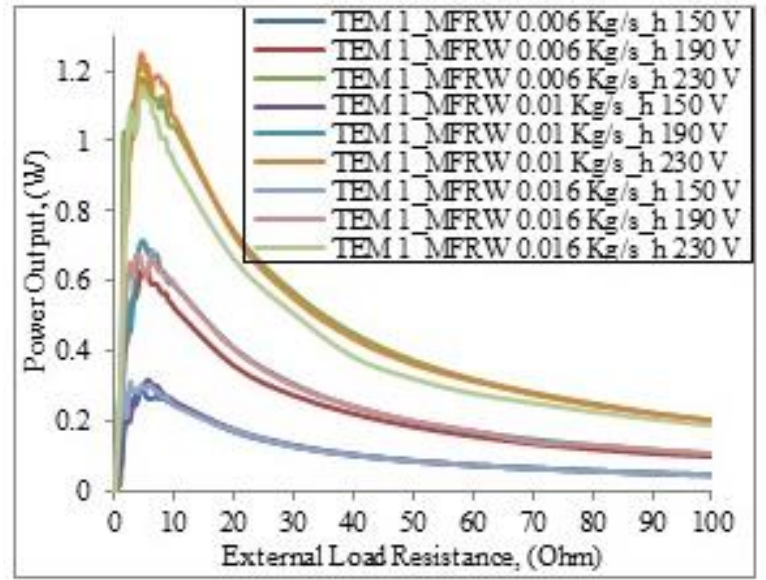

(A)

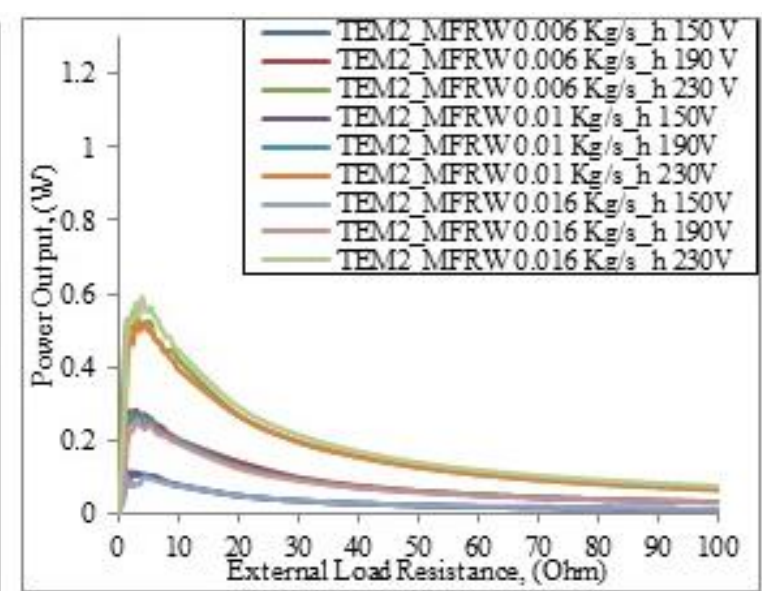

(B)

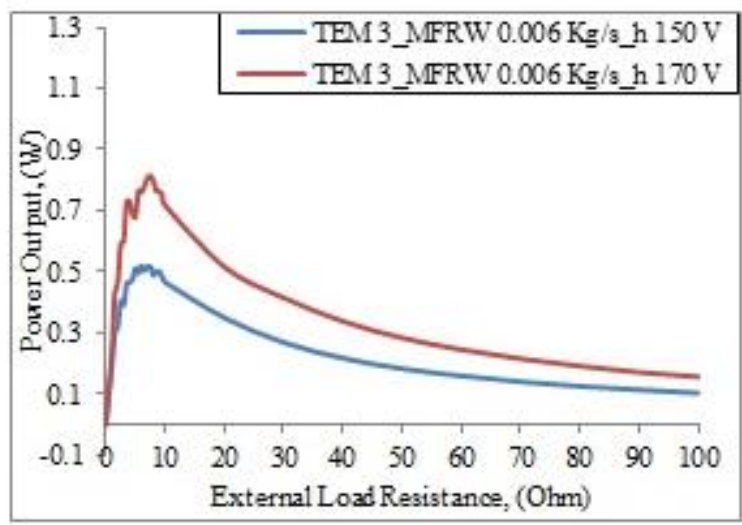

(C)

Figure 3 Variation of power output with external load resistance of (A) TEM1 (B) TEM2 (C) TEM3 for different mass flow rates of water and heater voltages

\section{RESULT AND DISCUSSION}

The performance of the thermoelectric module is control by temperature difference at hot and cold side of the thermoelectric module, and external load resistance. The performance of thermoelectric module is assessed at steady state condition. In the current work, four parameters with mix levels were used. The experimentations were carried out according to full factorial design of experiments. The experimental runs were conducted for various operating conditions such as; different thermoelectric modules of TEM1, TEM2, and TEM3, the heater voltage of 150, 190, and $230 \mathrm{~V}$, water mass flow rate of $0.006,0.010$, and 0.016 $\mathrm{Kg} / \mathrm{s}$, and external load resistance of 0 to $100 \Omega$ with different steps ( $0.5 \Omega$ for $0-10 \Omega$ range and $10 \Omega$ for $10-100 \Omega$ range), shown in table 5. Water mass flow rate of 0.006, 0.010 , and $0.016 \mathrm{Kg} / \mathrm{s}$ were considered for TEM1, TEM2 and 0.060 $\mathrm{Kg} / \mathrm{s}$ for TEM3. The heater voltage of 150,190 , and $230 \mathrm{~V}$ were considered for TEM1, TEM2 and 150, and $170 \mathrm{~V}$ for TEM3. The thermoelectric power output increasing with increasing external load resistance then decreases with increasing external load resistance. At specific external load resistance, maximum power output was obtained. Rapid changes in power output were found between 0 to $10 \Omega$ external load resistances, after that gradual change occurred. Figure 3 (A), (B), and (C) show power output variation of
TEM1, TEM2, and TEM3 with external load resistance respectively.

When external load resistance and internal material resistance are same, maximum power output can be obtained,. The thermoelectric power output increasing with increasing heater voltage of 150 to $230 \mathrm{~V}$. High heater voltages generate more temperature of the heater as well as hot side of the module. The temperature difference between hot side and cold side is more, maximum power output is obtained. The mass flow rate of cooling water shows mix result of thermoelectric power output. Generally, high mass flow rate of cooling fluid shows more heat transfer from cold side of the thermoelectric module and maintains low temperature, it creates more temperature difference between hot and cold side of the module. TEM1 shows maximum power output of $1.25 \mathrm{~W}$ at heater voltage of $230 \mathrm{~V}$, water mass flow rate of $0.010 \mathrm{Kg} / \mathrm{s}$ and external load resistance of $4.5 \Omega$. Maximum power output of $0.58 \mathrm{~W}$ at heater voltage of $230 \mathrm{~V}$, water mass flow rate of $0.016 \mathrm{Kg} / \mathrm{s}$, and eternal load resistance of $3 \Omega$ was achieved by TEM2. The TEM3 attained maximum power output of $0.81 \mathrm{~W}$ at heater voltage of $170 \mathrm{~V}$, water mass flow rate of $0.006 \mathrm{Kg} / \mathrm{s}$ and external load resistance of $7.5 \Omega$. The TEM1 shows maximum power output than TEM2 and TEM3.

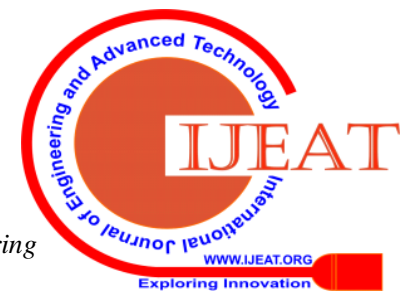


Figure 4 (A), (B), and (C) illustrate thermoelectric conversion efficiency deviations of TEM1, TEM2, and TEM3 with external load resistance respectively. The trend of the conversion efficiency curves is as same as power output curves.

TEM1 shows maximum conversion efficiency of $1.37 \%$ at heater voltage of $230 \mathrm{~V}$, water mass flow rate of $0.010 \mathrm{Kg} / \mathrm{s}$ and external load resistance of $4.5 \Omega$. Maximum conversion efficiency of $0.60 \%$ at heater voltage of $230 \mathrm{~V}$, water mass flow rate of $0.016 \mathrm{Kg} / \mathrm{s}$, and eternal load resistance of $3 \Omega$ was achieved by TEM2. The TEM3 attained maximum conversion efficiency of $1.64 \%$ at heater voltage of $170 \mathrm{~V}$, water mass flow rate of $0.006 \mathrm{Kg} / \mathrm{s}$ and external load resistance of $7.5 \Omega$. The TEM3 shows maximum conversion efficiency than TEM1 and TEM2.

The conclusion is that the maximum power output and maximum conversion efficiency was obtained at the same water mass flow rate, heater voltage and external load resistance.

The voltage output of the thermoelectric module decreases with increasing current and the power out increases with increasing current, after achieving maximum power output, it decreases with increasing current. The same trend was obtained for thermoelectric module of TEM1, TEM2, and TEM3 at different mass flow rates of water and heater voltages. The maximum voltage obtained at current of 0 ampere and external load resistance of $0 \Omega$ is called open circuit voltage. Figure 5 (A), (B), and (C) show that the voltage output and power output variation of TEM1 with current output at water mass flow rate of 0.006, 0.010, and $0.016 \mathrm{Kg} / \mathrm{s}$ and different heater voltages respectively. The figure 5 (A) illustrates, maximum voltage of $4.66 \mathrm{~V}$ and maximum power output of $1.19 \mathrm{~W}$ was obtained at water flow rate of $0.006 \mathrm{Kg} / \mathrm{s}$ and heater voltage of $230 \mathrm{~V}$. The maximum voltage of $4.69 \mathrm{~V}$ and maximum power output of $1.25 \mathrm{~W}$ was attended at water flow rate of $0.010 \mathrm{Kg} / \mathrm{s}$ and heater voltage of $230 \mathrm{~V}$, shown by the figure 5 (B).

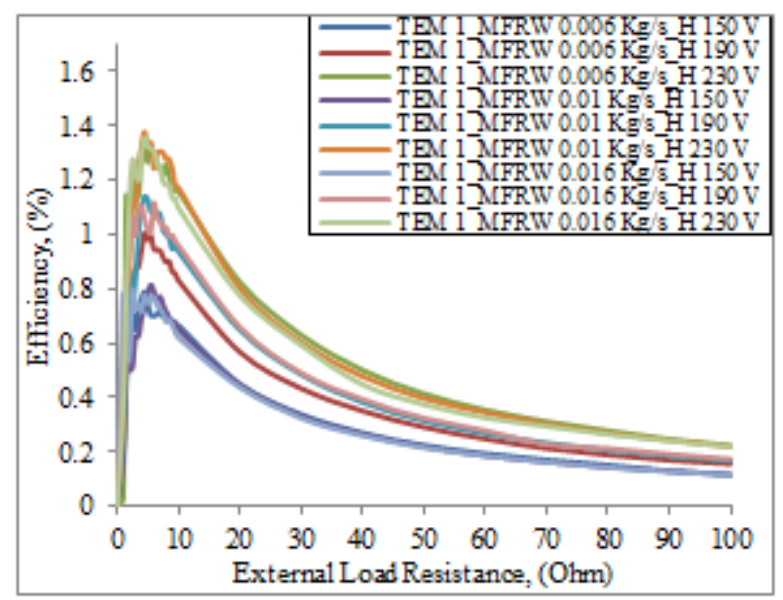

(A)

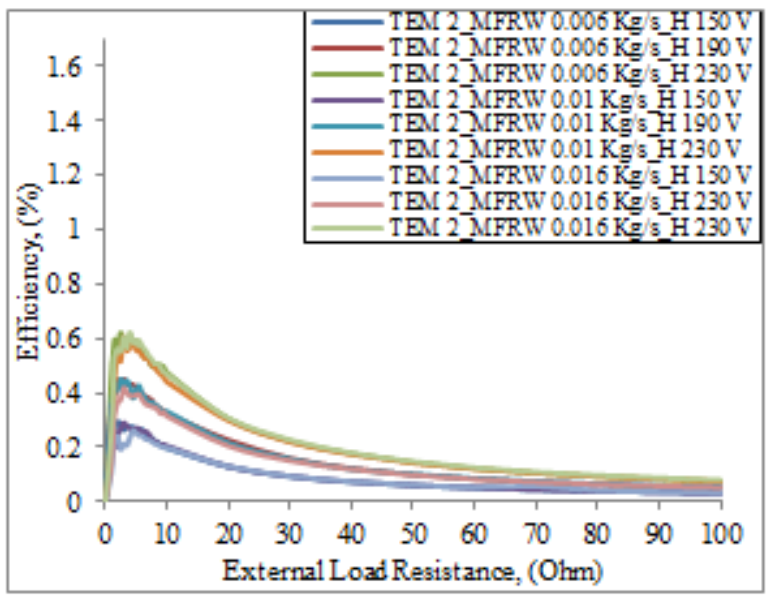

(B)

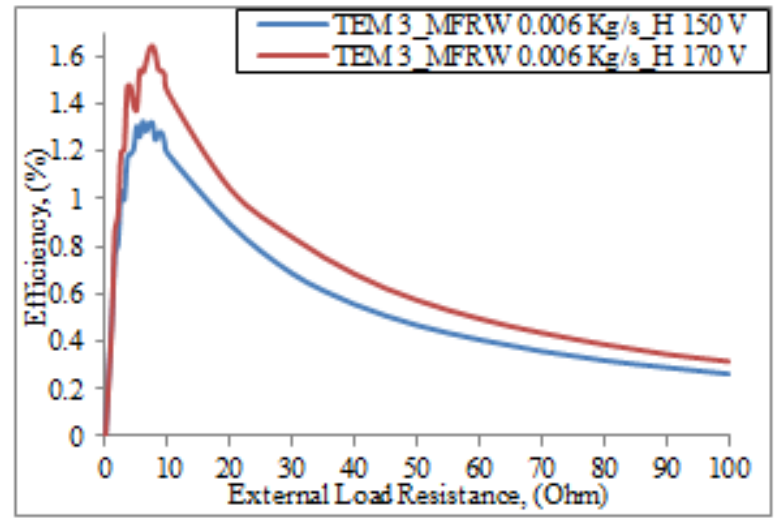

(C)

Figure 4 Variation of conversion efficiency with external load resistance of (A) TEM1 (B) TEM2 (C) TEM3 for different mass flow rates of water and heater voltages 


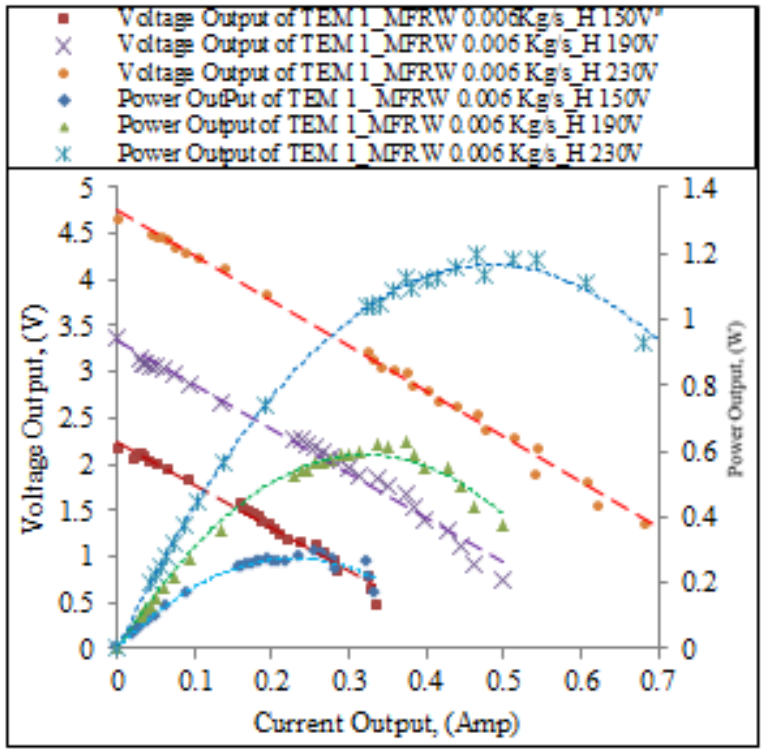

(A)

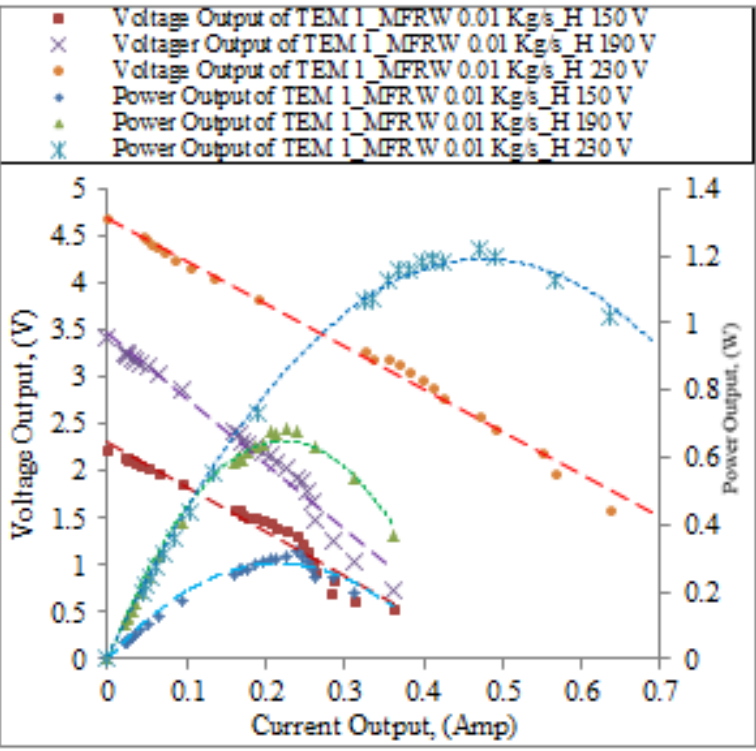

(B)

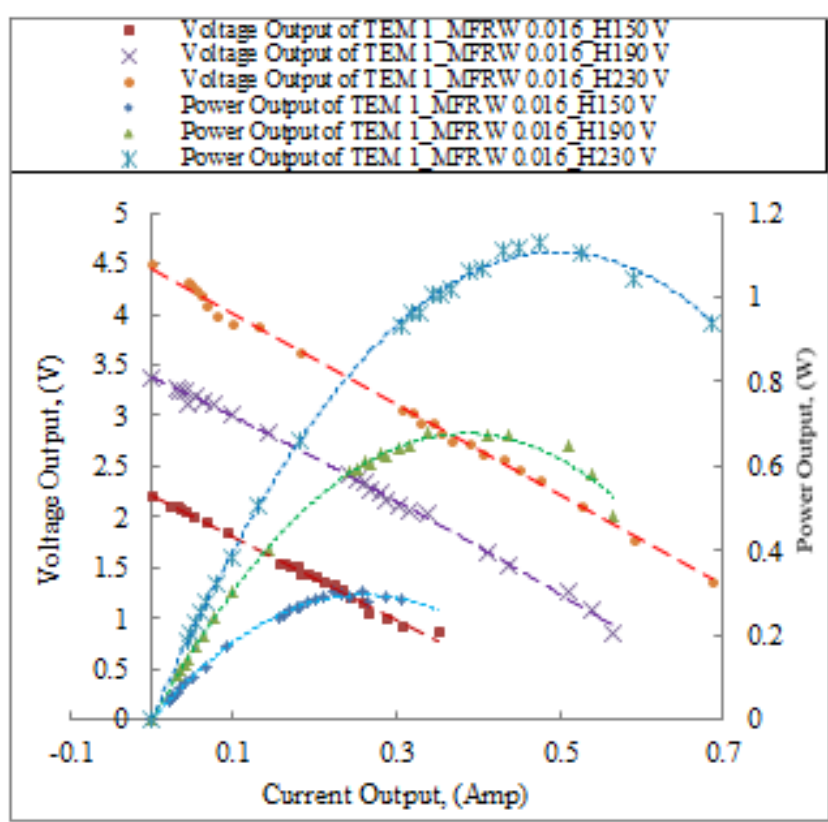

(C)

Figure 5 Variation of voltage and power output of TEM1 with current at (A) $0.006 \mathrm{Kg} / \mathrm{s}$ (B) $0.010 \mathrm{Kg} / \mathrm{s}$ (C) $0.016 \mathrm{Kg} / \mathrm{s}$ mass flow rate of water and different heater voltages

In the same way, figure 5 (C) shows maximum voltage of $4.5 \mathrm{~V}$ and maximum power output of $1.15 \mathrm{~W}$ was achieved at water flow rate of $0.016 \mathrm{Kg} / \mathrm{s}$ and heater voltage of $230 \mathrm{~V}$. It was revealed that maximum voltage was obtained at heater voltage of $230 \mathrm{~V}$ and water flow rates of 0.010 and 0.016 $\mathrm{Kg} / \mathrm{s}$. Figure $6(\mathrm{~A})$, (B), and (C) show voltage output and power output variation of TEM2 with current output at water mass flow rate of $0.006,0.010$, and $0.016 \mathrm{Kg} / \mathrm{s}$ and different heater voltages respectively. The figure 6 (A) illustrates, maximum voltage of $2.65 \mathrm{~V}$ and maximum power output of $0.55 \mathrm{~W}$ was obtained at water flow rate of $0.006 \mathrm{Kg} / \mathrm{s}$ and heater voltage of $230 \mathrm{~V}$. The maximum voltage of $2.69 \mathrm{~V}$ and maximum power of $0.54 \mathrm{~W}$ was attended at water flow rate of $0.010 \mathrm{Kg} / \mathrm{s}$ and heater voltage of $230 \mathrm{~V}$, shown by the figure 6 (B). In the same way, figure 6 (C) shows maximum voltage of $2.85 \mathrm{~V}$ and maximum power output of $0.58 \mathrm{~W}$ was achieved at water flow rate of $0.016 \mathrm{Kg} / \mathrm{s}$ and heater voltage of $230 \mathrm{~V}$. It was observed that maximum voltage was obtained at heater voltage of $230 \mathrm{~V}$ and water flow rates of $0.016 \mathrm{Kg} / \mathrm{s}$. Figure 7 show voltage output and power output variation of TEM3 with current output at water mass flow rate of $0.006 \mathrm{Kg} / \mathrm{s}$ and different heater voltages of 150 , and $170 \mathrm{~V}$. The figure 7 illustrates maximum voltage of $4.20 \mathrm{~V}$ and maximum power output of $0.81 \mathrm{~W}$ was obtained at water flow rate of $0.006 \mathrm{Kg} / \mathrm{s}$ and heater voltage of $170 \mathrm{~V}$. The conclusion is that the TEM1 shows maximum voltage of 4.69 $\mathrm{V}$ and maximum power output of $1.25 \mathrm{~W}$, achieved at water mass flow rate of $0.010 \mathrm{Kg} / \mathrm{s}$ and heater voltage of $230 \mathrm{~V}$.

The hot side temperature of thermoelectric modules was divided in to three ranges of $80-100{ }^{\circ} \mathrm{C}, 100-150{ }^{\circ} \mathrm{C}$ and $150-200{ }^{\circ} \mathrm{C}$. Figure 8 illustrates that the maximum power output varies with various hot side temperature of thermoelectric modules (TEM1, TEM2 and TEM3).

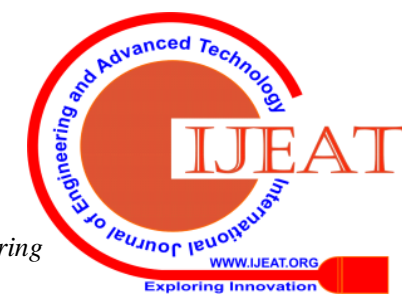


The power output of the thermoelectric module increases with increasing hot side temperature of the modules. The first range of hot side temperature, TEM1 and TEM2 show maximum power output of $0.32 \mathrm{~W}$ and $0.11 \mathrm{~W}$ respectively. The second range of hot side temperature, TEM1, TEM2, and TEM3 show maximum power output of $0.71,0.28$, and 0.81 $\mathrm{W}$ respectively. The third range of hot side temperature, TEM1 and TEM2 show maximum power output of 1.25 and $0.59 \mathrm{~W}$ respectively. So, the conclusion is that TEM1 is appropriate for first range of hot side temperature. TEM1 and TEM3 are the most suitable for second range of hot side temperature. And the TEM1 is mostly applicable for third range of hot side temperature.
The thermoelectric module having more Seebeck coefficient shows more figure of merit. The thermoelectric modules with high figure of merit can generate more power output. Figure 9 represents the maximum Seebeck coefficient verses hot side temperature of thermoelectric module. The hot side temperature of thermoelectric module is divided in three zones, zone I (80-100 $\left.{ }^{\circ} \mathrm{C}\right)$, zone II $\left(100-150{ }^{\circ} \mathrm{C}\right)$, and zone III (150-200 $\left.{ }^{\circ} \mathrm{C}\right)$. For zone I, the TEM 1 shows maximum Seebeck coefficient of 0.0409 at water mass flow rate of $0.016 \mathrm{Kg} / \mathrm{s}$ and hot side temperature of $88.58{ }^{\circ} \mathrm{C}$. For zone II, the TEM3 shows maximum Seebeck coefficient of 0.0440 at water mass flow rate of $0.006 \mathrm{Kg} / \mathrm{s}$ and hot side temperatureof $138.36^{\circ} \mathrm{C}$.

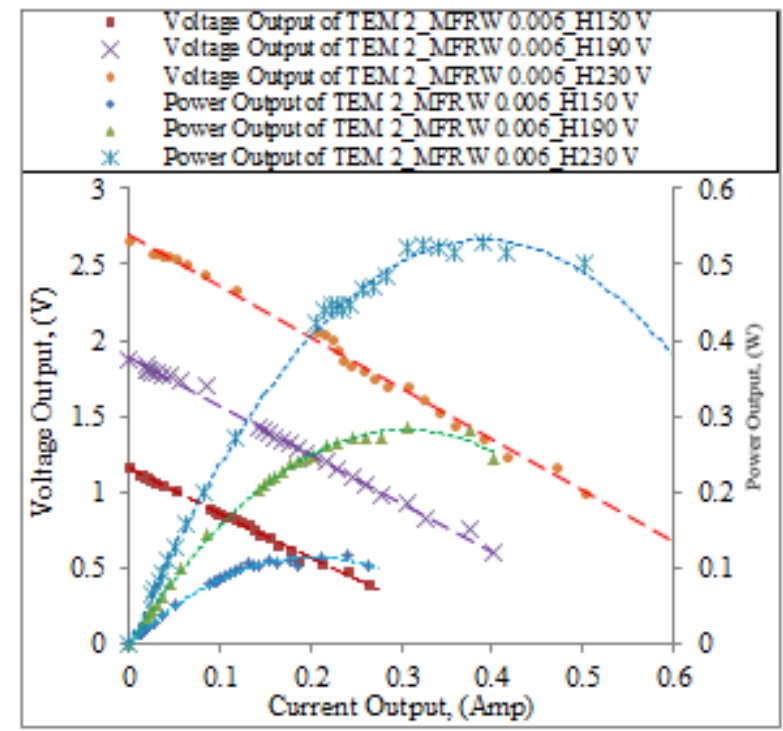

(A)

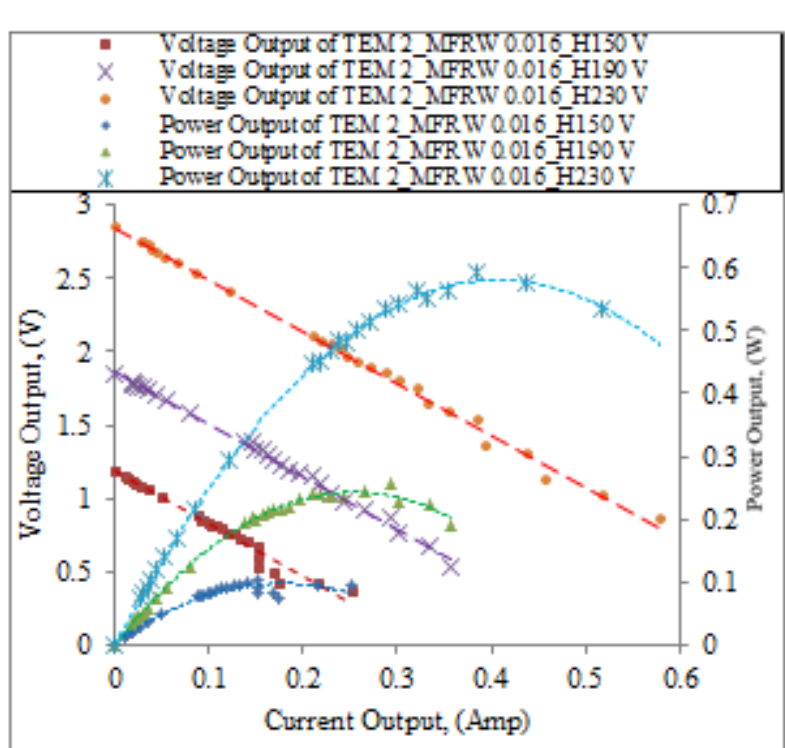

(C)

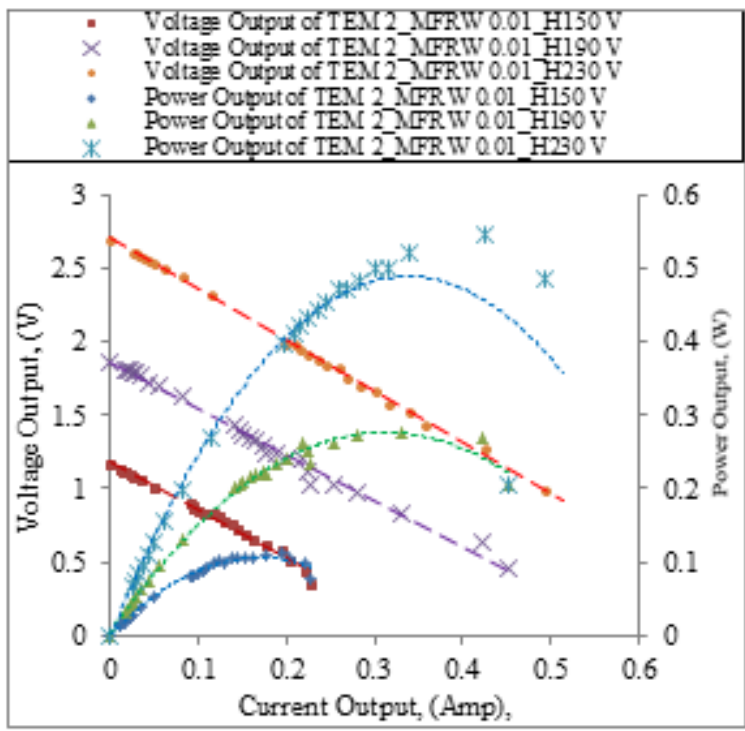

(B)

Figure 6 Variation of voltage and power output of TEM2 with current at (A) $0.006 \mathrm{Kg} / \mathrm{s}$ (B) $0.010 \mathrm{Kg} / \mathrm{s}$ (C) $0.016 \mathrm{Kg} / \mathrm{s}$ mass flow rate of water and different heater voltages 


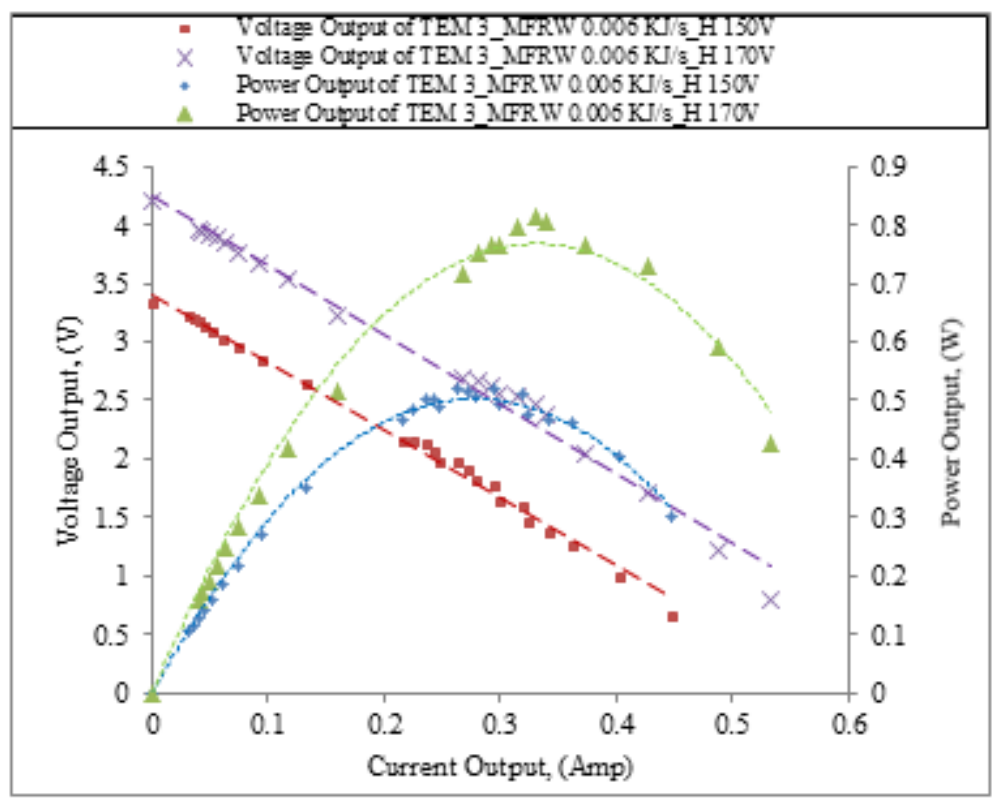

Figure 7 Variation of voltage and power output of TEM3 with current at mass flow rate of water, $0.006 \mathrm{Kg} / \mathrm{s}$ and various heater voltage, $150,170 \mathrm{~V}$

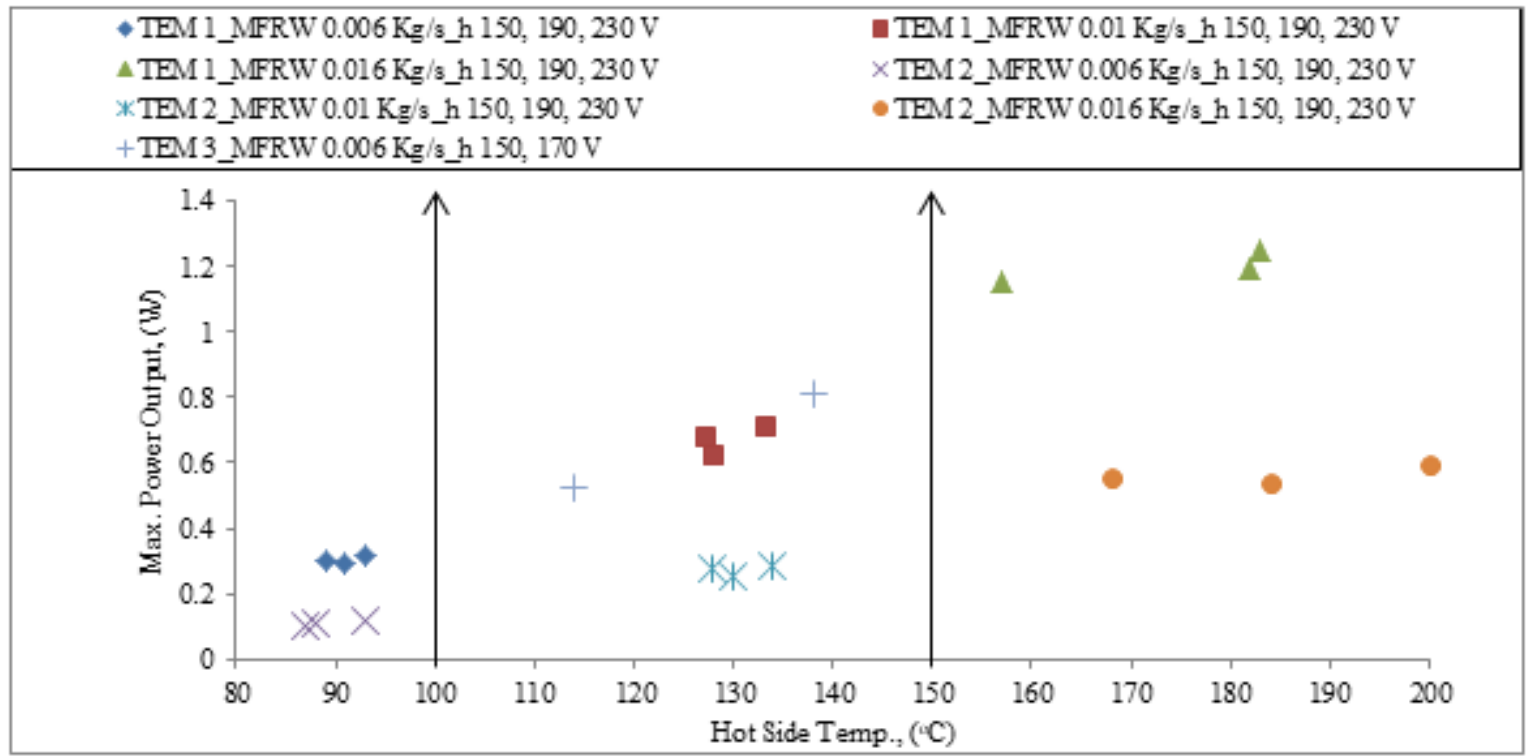

Figure 8 Maximum power output of TEM1, TEM2, and TEM3 with hot side temperature at different mass flow rates of water and heater voltages

For zone III, the TEM 1 shows maximum Seebeck coefficient of 0.0351 at water mass rate of $0.016 \mathrm{Kg} / \mathrm{s}$ and hot side temperature of $157.41{ }^{\circ} \mathrm{C}$. For zone I and III, the TEM 1 is suitable for maximum power generation. For zone II TEM 3 is more appropriate module for generation of maximum power output.

Figure 10 shows the variation of maximum power output and conversion efficiency of thermoelectric modules with temperature difference. The power out and conversion efficiency increases with increasing the temperature difference. The temperature difference of the thermoelectric module is categorized in to two zones, zone $\mathrm{I}\left(50-110^{\circ} \mathrm{C}\right)$ and zone II $\left(110-170{ }^{\circ} \mathrm{C}\right)$. For zone I, TEM1 and TEM3 show more power output and TEM3 shows more efficiency than TEM1 and TEM2. For zone II, TEM1 shows more power output as well as conversion efficiency than TEM2. In the zone II, the increasing rate of power output is more than increasing rate of conversion efficiency. The TEM1and TEM3 are suitable for zone I and TEM1 is more appropriate for zone II. It is observed that the TEM1 is best thermoelectric module for maximum power generation. 


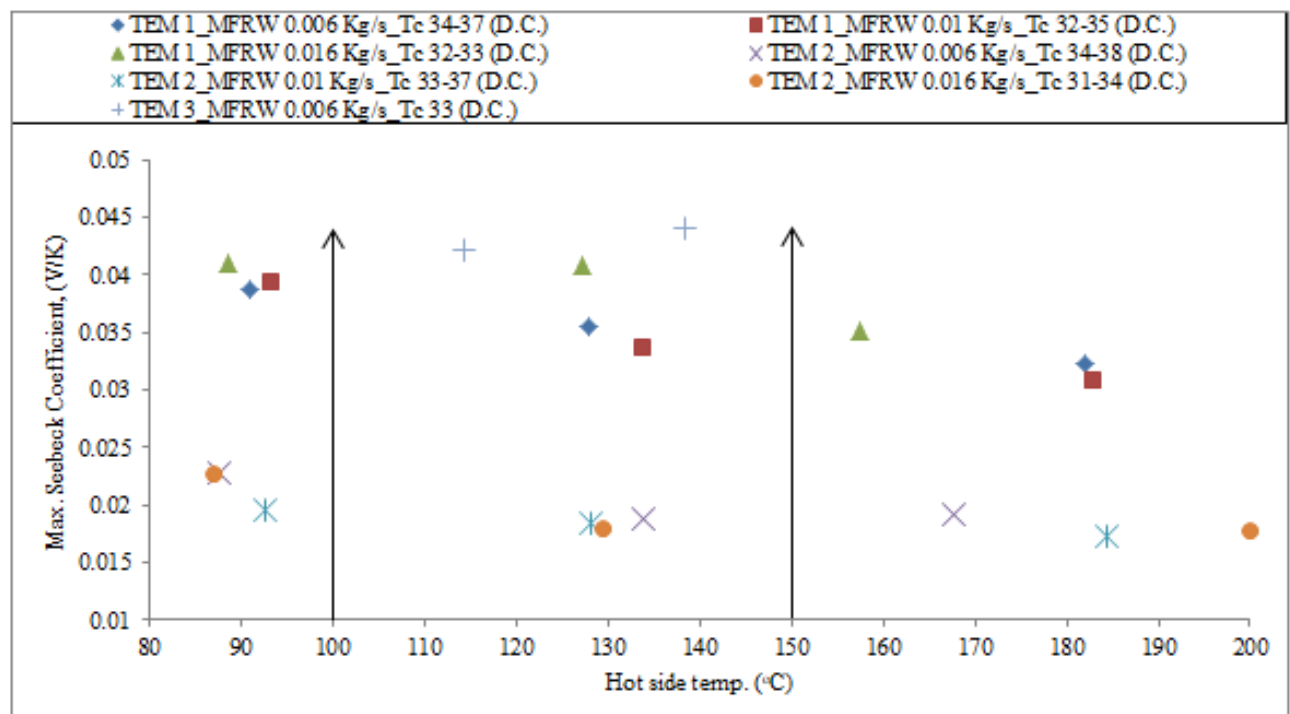

Figure 9 Maximum Seebeck coefficients of TEM1, TEM2, and TEM3 with hot side temperature at different mass flow rates of water and cold side temperature

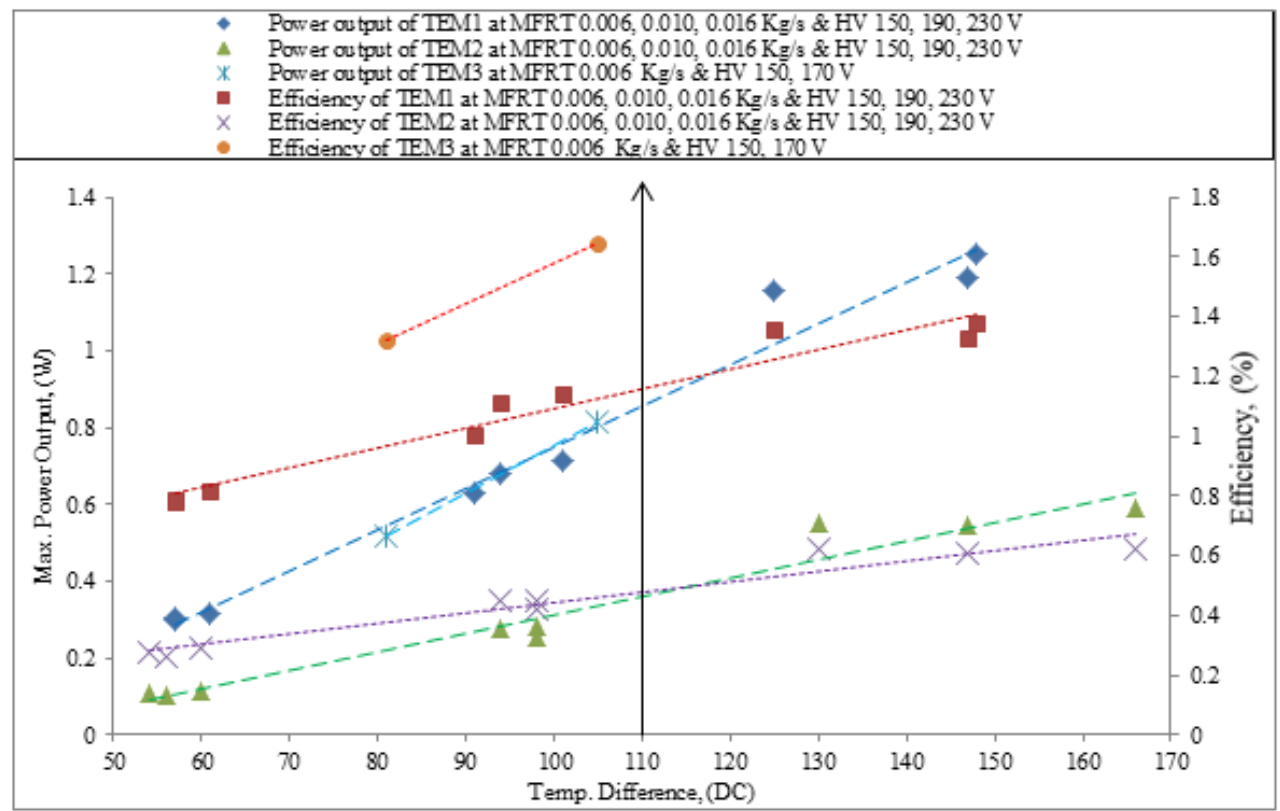

Figure 10 Variation of maximum power outputs and conversion efficiency of TEM1, TEM2, and TEM3 with temperature difference at different mass flow rates of water and heater voltages.

\section{CONCLUSIONS}

In the current work, thermoelectric modules were tested for low-temperature heat recovery to find the best performance thermoelectric module. According to literature survey, bismuth telluride thermoelectric modules were used by the researchers for low temperature heat recovery. There are three commercial (low-temperature) Bismuth Telluride $\left(\mathrm{Bi}_{2} \mathrm{Te}_{3}\right)$ thermoelectric modules were selected for this work for finding the effect of different operating conditions on performance of the modules. Different kinds of operating conditions were used for experimentation, such as heater voltage, mass flow rate of water, thermoelectric modules and external load resistance. The experimentations were carried out at steady state conditions. The performance of thermoelectric generator was measure in terms of power output and conversion efficiency.

According to result and discussion of this experimentation work, it is observed that the TEM1 is more appropriate thermoelectric module for temperature range of $80-200{ }^{\circ} \mathrm{C}$. The TEM3 is also suitable for the temperature range of 80-150 ${ }^{\circ} \mathrm{C}$ but it can't work for temperature more than 150 ${ }^{\circ} \mathrm{C}$. The TEM2 is not applicable for the temperature range of $80-200{ }^{\circ} \mathrm{C}$, It may be suitable for higher temperature range of 250-300 ${ }^{\circ} \mathrm{C}$. In future, this work would be a support for selection of appropriate thermoelectric module and design of thermoelectric system for more power output and conversion efficiency.

\section{ACKNOWLEDGMENT}

The first author is a research scholar in mechanical engineering department of G. H. Raisoni College of Engineering, Nagpur, 440016, India. The authors acknowledge Dr. Preeti Bajaj, Director GHRCE, Nagpur, India, for her motivation, guidance and support of this work.

Published By:

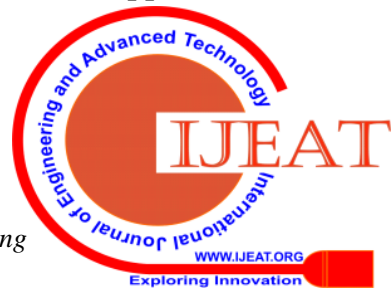




\section{REFERENCES}

1. Tzeng Sheng-Chung, Jeng Tzer-Ming, Lin Yi-Liang., "Parametric study of heat transfer design on the thermoelectric generator system," International Communications in Heat and Mass Transfer, vol. 52, 2014, pp. 97-105.

2. Su CQ, Wang WS, Liu X, Deng YD., "Simulation and experimental study on thermal optimization of the heat exchanger for automotive exhaust-based thermoelectric generators," Case Stud Thermal Engineering, vol. 4, 2014, pp. 85-91.

3. Kumar C Ramesh, Sonthalia Ankit, Goel Rahul., "Experimental study on waste heat recovery from an internal combustion engine using thermoelectric technology," Thermal Science, vol. 15, 2011, pp 1011-1022.

4. Liu X, Deng YD, Chen S, Wang WS, Xu Y, Su CQ., "A case study on compatibility of automotive exhaust thermoelectric generation system, catalytic converter and muffler," Case Stud Thermal Engineering, vol. 2, 2014, pp. 62-66.

5. Hsu Cheng-Ting, Huang Gia-Yeh, Chu Hsu-Shen, Yu Ben, Yao Da-Jeng., "Experiments and simulations on low-temperature waste heat harvesting system by thermoelectric power generators," Applied Energy, vol. 88, 2011, pp. 1291-1297.

6. Lu Hongliang, Wu Ting, Bai Shengqiang, Xu Kangcong, Huang Yingjie, Gao Weimin, Yin Xianglin, Chen Lidong., "Experiment on thermal uniformity and pressure drop of exhaust heat exchanger for automotive thermoelectric generator," Energy, vol. 54, 2013, pp. 372-377.

7. Deng YD, Liu X, Chen S, Tong NQ., "Thermal optimization of the heat exchanger in an automotive exhaust-based thermoelectric generator," Journal of Electronic Materials, vol. 42, 2013, pp. 1634-1640.

8. Su CQ, Zhan WW, Shen S., "Thermal optimization of the heat exchanger in the vehicular waste-heat thermoelectric generations," Journal of Electronic Materials, vol. 41, 2012, pp. 1693-1697.

9. Chrastina D, Cecchi S, Hague JP, Frigerio J, Samarelli A, Ferre-Llin L, Paul DJ, Müller E, Etzelstorfer T, Stangl J, Isella G., "Ge/SiGe superlattices for nanostructured thermoelectric modules," Thin Solid Films, vol.543, 2013, pp. 153-156.

10. LeBlanc Saniya, "Thermoelectric generators: linking material properties and systems engineering for waste heat recovery applications," Sustainable Materials and Technologies, vol. 1 (2), 2014, pp. 26-35.

11. Rowe DM., "Thermoelectric generators as alternative sources of low power," Renewable Energy, vol. 5, 1994, pp. 1470-8.

12. Rowe DM., "Applications of nuclear-powered thermoelectric generators in space," Applied Energy, vol. 40, 1991, pp. 241-271.

13. Elsheikh Mohamed Hamid, Shnawah Dhafer Abdulameer, MohdSabri MohdFaizul, MohdSaid Suhana Binti, Hassan Masjuki Haji, AliBashir Mohamed Bashir, Mohamad Mahazani., "A review on thermoelectric renewable energy: principle parameters that affect their performance," Renewable and Sustainable Energy Reviews, vol. 30, 2014, pp. 337-55.

14. He Wei, Zhang Gan, Zhang Xingxing, Ji Jie, Li Guiqiang, Zhao Xudong., "Recent development and application of thermoelectric generator and cooler," Appled Energy, vol. 143, 2015, pp. 1-25.

15. Karabetoglu Sevan, Sisman Altug, Ozturk Z Fatih, Sahin Turker., "Characterization of a thermoelectric generator at low temperatures," Energy Conversion and Managemen, vol. 62, 2012, pp. 47-50.

16. Ian T. Witting, Thomas C. Chasapis, Francesco Ricci, Matthew Peters, Nicholas A. Heinz, Geoffroy Hautier, and G. Jeffrey Snyder., "The Thermoelectric Properties of Bismuth Telluride," Advanced electronic materials, vol.- , 2019, pp. 1-20.

17. Wang Tongcai, Luan Weiling, Wang Wei, Tu Shan-Tung., "Waste heat recovery through plate heat exchanger based thermoelectric generator system," Applied Energy, vol. 136, 2014, pp. 860-865.

18. Chen Xiaozong, Liu Leifeng, Dong Yuan, Wanga Lianjun, Chen Lidong, Jiang Wan., "Preparation of nano-sized Bi2Te3 thermoelectric material powders by cryogenic grinding," Progress in Natural Science: Materials International, vol. 22 (3), 2012, pp. 201-206.

19. Weng Chien-Chou, Huang Mei-Jiau., "A simulation study of automotive waste heat recovery using a thermoelectric power generator," International Journal of Thermal Science, vol. 71, 2013, pp. 302-309.

20. Gen Li, Zhongcheng Wang, Feng Wang, Xiaozhong Wang, Shibo Li and Mingsuo Xue., "Experimental and Numerical Study on the effect of Interfacial Heat Transfer on Performance of Thermoelectric Generators," Energies, vol. 12, 2019, pp. 1-14.

21. Mengjun Zhang, Yuanyuan Tian, Huaqing Xie, Zihua Wu, Yuanyuan Wang., "Influence of Thomson effect on the thermoelectric generator. International Journal of Heat and Mass Transfer", vol. 137, 2019, pp. 1183-1190.

22. Rowe DM., "Thermoelectrics, an environmentally-friendly source of electrical power," Renewable Energy, vol. 16, 1999, pp. 1251-1256.
23. Montecucco Andrea, Knox Andrew R., "Accurate simulation of thermoelectric power generating systems," Applied Energy, vol. 118, 2014, pp. 166-172.

24. Karthikeyan, B. and Kesavram, D., "Exhaust energy recovery using thermoelectric power generation from a thermally insulated diesel engine," International Journal of Green Energy, vol. 10 (10), 2013, pp. 1056-1071.

25. Bowen Cai, Haihua Hu, Hua-Lu Zhuang, Jing-Feng., "Promising materials for thermoelectric applications," Journal of Alloys and Compounds, vol. 806, 2019, pp. 471-486.

26. Bai Shengqiang, Lu Hongliang, Wu Ting, Yin Xianglin, Shi Xun, Chen Lidong., "Numerical and experimental analysis for exhaust heat exchangers in automobile thermoelectric generators," Case Studuty-Thermal Engineering, vol. 99, 2014, pp. 99-112.

27. Amaral Calil, Brandão Caio, Sempels Éric V, Lesage Frédéric J., "Net thermoelectric generator power output using inner channel geometries with alternating flow impeding panels," Applied Thermal Engineering, vol. 94, 2014, pp. 94-101.

28. Niu Zhiqiang, Diao Hai, Yu Shuhai, Jiao Kui, Du Qing, Shu Gequn., "Investigation and design optimization of exhaust-based thermoelectric generator system for internal combustion engine," Energy Conversion and Managemen, vol. 85, 2014, pp. 85-101.

29. Wang Yiping, Li Shuai, Yang Xue, Deng Yadong, Su Chuqi., "Numerical and experimental investigation for heat transfer enhancement by dimpled surface heat exchanger in thermoelectric generator," Journal of Electronic Materials, vol. 45 (3), 2015, pp. 1792-1802

30. Dai a Dan, Zhou b Yixin, Liu Jing., "Liquid metal based thermoelectric generation system for waste heat recovery" Renew Energy, vol. 36, 2011, pp. 3530-3536.

31. Wang Tongcai, Luan Weiling, Wang Wei, Tu Shan-Tung., "Waste heat recovery through plate heat exchanger based thermoelectric generator system," Applied Energy, vol. 136, 2014, pp. 860-865.

\section{AUTHORS PROFILE}

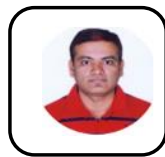

Mr. Dipak S. Patil is a research scholar in Mechanica Engineering Department of G. H. Raisoni College of Engineering Nagpur, Maharashtra, India. He has completed M. Tech. in thermal and fluids from Dr. Babasaheb Ambedkar Technological University, Lonere, Raygad, Maharshtra, India. His area of interest is waste heat recovery, material science and Heat Transfer.

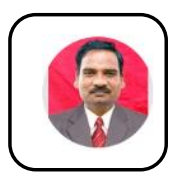

Dr. Rachayya R. Arakerimath is a Professor and Head of Mechanical Engineering Department of G. H. Raisoni College of Engineering and management, Wagholi, Pune, India. He has completed $\mathrm{PhD}$ from Visvesvaraya Technological University (VTU), Karnataka, India. His area of interest is CAD/CAM/CAE.

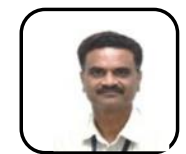

Dr. Pramod V. is a Deputy Director and Dean IQAC of G. H. Raisoni College of Engineering Nagpur, India. He has completed M. Tech. in Heat Power Engineering and $\mathrm{PhD}$ in Mechanical Engineering from VNIT, Nagpur, India. His area of interest is unconventional energy sources and Energy Conversion.

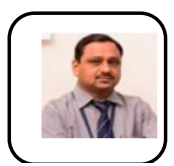

Dr. Rupesh S. Shelke is a Professor and Head of Mechanical Engineering Department of G. H. Raisoni College of Engineering, Nagpur, India. He has completed M. Tech. in Heat Power Engineering and $\mathrm{PhD}$ in Mechanical Engineering from VNIT, Nagpur, India. His area of interest is unconventional energy sources, and $\mathrm{H}$. T. 